\section{Infections in Relation to Perito- neal Dialysis: An 11-Year Single Center Experience in Vestfold County, Norway}

\author{
Thea Bjune, Stig Arne Kjellevold and Sadollah Abedini* \\ Vestfold Hospital Trust, Medical clinic, Department of Nephrology, Toensberg, \\ Norway
}

\begin{abstract}
\section{Introduction}

The use of Peritoneal Dialysis (PD) in Norway has been limited compared to other western countries. PD is considered a good alternative to hemodialysis and the method is cost-effective. Infections related to $\mathrm{PD}$ are still the most frequent complication and often limits the extent of its use.
\end{abstract}

\section{Methods}

We identified all patients receiving PD-catheters in the district County Hospital of Vestfold during 11 years. All information was collected retrospectively through examination of patient charts and data from the local PD complication registry.

\section{Results}

$65 \%$ were male $(n=66)$ with median age 67 years $(18-94)$. Cause of end-stage renal failure were hypertension $27 \%$, diabetic nephropathy $16 \%$, glomerulonephritis $23 \%$ and others $35 \%$.

In total, 89 patients were initiated on PD. $2 \%$ of the patients developed postoperative infections. Exit site infections occurred in 43 $(43 \%)$ patients. Staphylococcus aureus was the major cause of both exit site and peritoneal infections. The incidence of peritonitis was 0.65 episodes per patient year. Age older than 75 years was not associated with higher risk of infection. Female gender carries a higher peritonitis risk in multivariate analysis.

69 (69\%) patients discontinued PD: Of these 30 (30\%) received

*Corresponding author: Sadollah Abedini, Vestfold Hospital Trust, Medical clinic, Department of Nephrology, Toensberg, Norway, Tel: +47 33342000; E-mail: sadollah.abedini@siv.no

Citation: Bjune T, Kjellevold SA, Abedini S (2020) Infections in Relation to Peritoneal Dialysis: An 11-Year Single Center Experience in Vestfold County, Norway. J Nephrol Renal Ther 6: 029.

Received: May 12, 2020; Accepted: May 22, 2020; Published: May 30, 2020

Copyright: (c) 2020 Bjune T, et al. This is an open-access article distributed under the terms of the Creative Commons Attribution License, which permits unrestricted use, distribution, and reproduction in any medium, provided the original author and source are credited. kidney transplants, 14 (14\%) due to PD related infections, 8 due to non-infectious complications, 9 (9\%) patients died during PD and 7 patients were discontinued PD due to terminal disease.

\section{Conclusion}

In our experience, the occurrence of PD related infections are low. Infections were however the reason for conversion to hemodialysis in some patients. In our population, PD is a safe bridge to kidney transplantation. We observed no excess risk of infection among the elderly and PD can be considered a safe treatment option. Female gender carries higher risk for peritonitis.

Keywords: Excite site infection; Peritoneal dialysis; Peritonitis; Renal replacement therapy; Tunnel infection

\section{Introduction}

The prevalence of Chronic Kidney Disease (CKD) in Norway is $10.2 \%$. CKD is defined as GFR $<90 \mathrm{ml} / \mathrm{min}$ per $1,73 \mathrm{~m}^{2}$ and albuminuria [1]. In Norway, the most common causes of End-Stage Renal Disease (ESRD) requiring Renal Replacement Therapy (RRT), is due to hypertension $27 \%$, diabetes mellitus $17 \%$, polycystic kidney disease $10 \%$, immunological or systemic disease $10 \%$ and glomerulonephritis $8 \%$ [2]. By the end of 2018, 5256 patients received RRT $(986.5$ per million inhabitants) in Norway. Of these, $348(6.6 \%)$ patients received Peritoneal Dialysis (PD), 1284 (24.4\%) Hemodialysis (HD) and 3624 (68.9\%) (Received Kidney Transplantation (RTx)). Median age was 62 years, mean 59.9 years ranging from 0.9-96.4 years. The RRT population were predominately male (64.5\%) [2].

PD is proposed as an optimal treatment modality in about one third of all patients requiring dialysis [1]. However, the proportion of patients receiving PD or HD differs between countries and different regions in the same country. Variation in the provided dialysis modality are multifactorial and not fully understood [3-5].

Patient on RRT have increased morbidity and mortality, regardless of the type of RRT; comorbidity due to diabetes or hyper- or hypotension have a worse outcome. Residual renal function is associated with better outcome [6].

PD elaborated in the late 1800's and was performed on human for the first time in 1923. The first indwelling tenckhoff catheter was used in 1968 for PD access. Continuous Ambulatory PD (CAPD) was taken into clinical use in 1978 [6-8]. For successful PD the patient has to meet several requirements, however inflammatory bowel disease, active Clostridium difficile infection, unrepaired hernias and liver failure with ascites are the most important contraindications for PD [9].

PD utilization had its peak in the US between 1982 and 1985, but has decreased during the last decades $[10,11]$. There are several studies comparing $\mathrm{HD}$ to $\mathrm{PD}$, some suggesting PD to be inferior to HD $[1,6,10]$. However, many of these studies are poorly designed. Several studies worldwide suggest better survival with PD compared to HD, and $\mathrm{PD}$ is considered a safe and patient friendly treatment [6]. 
The overall risk of death is highest during the first years of RRT [12]. More than $50 \%$ of deaths in both PD and HD are due to cardiovascular events [6]. Some studies suggest that RRT initiated with PD is more likely to have a better graft survival in patients undergoing Kidney transplantation (KTx) later on $[11,13]$. Utilization of PD differs between countries. The worldwide prevalence of PD is $11 \%$ [3]. Countries such as Mexico, Canada, New Zealand, Australia and Hong Kong use PD at a wider extent $[1,6]$. As in other western countries with low PD utilization, PD is only used in $6.6 \%$ of patients on RRT in Norway $[2,14]$.

There are several reasons for variation in PD utilization between countries. These relate to economical/ reimbursement issues and lack of expertise training and knowledge $[10,11,14,15]$. However PD-related infections, or rather the fear of them, is thought to be the main reason for low use of PD $[1,10,14]$. It is important to emphasize that infections are more common in HD, with septicemia as the most important condition, due to catheter-infection and increased mortality [14].

The most common complication of PD are infections limited to the peritoneal cavity $[10,16]$. Type of infection is defined in relation to the anatomical site; exit-site infection, tunnel-infection and peritonitis [17]. They can occur independently, or in combination.

An exit-site infection can occur as both an acute and a chronic infection and sometimes lasting several weeks despite sufficient treatment. Treatment is based on microbiological findings and consist of local or systemic antibiotics. A tunnel infection is treated with broad-specter Intravenous (IV)/Intraperitoneal (IP) antibiotic until microbiological findings. Peritonitis as the most important infectious complication, is suspected when the patient present with fever and abdominal pain, opalescent dialysate, or a combination of these. It requires IV and IP antimicrobial treatment for several weeks $[17,18]$. If the external cuff is extruded one should consider cuff-shaving to prevent recurrent infections [19].

There are specific indications for catheter removal, which lead to a pause or termination in PD [18]. The rare and serious complication of Encapsulating Peritoneal Sclerosis (EPS) is feared, but is not thought to be related to peritonitis $[11,20]$. After one episode of peritonitis there is an increased risk of death following the first month, then the risk is reduced during the next half year [6,11]. Peritonitis is the most common cause of terminating PD-treatment [14].

Risk factors for peritonitis in PD was assessed in a large Canadian study from 2009 including more than 4000 patients. Age, black race, conversion from HD to $\mathrm{PD}$, diabetes in women and poor glycemic control is associated with increased risk and shorter time to first peritonitis $[6,21]$. Previous peritonitis is described as a risk factor for future peritonitis [17]. Different types of PD modalities Continuous Ambulatory Peritoneal Dialysis (CAPD) and Automated Peritoneal Dialysis (APD) carry the same risk of developing peritonitis [21].

The rate of peritonitis has decreased worldwide during the last 10-20 years, but the rates varies both between countries and between centers in the same country. This is largely due to different practices in training of staff, use of prophylactic antibiotics and varieties in guidelines and the different use of them [6].

We report our experience with PD related infections from a single center study during 11 years of follow-up in Vestfold County
(Inhabitant aprox. 245.000) in Norway. Our primary objective was to assess the occurrence of PD related exit site infection and peritonitis. Secondary we wanted to evaluate how important individual patient characteristics influence the occurrence of PD related infections.

\section{Materials and Methods}

All patients in Norway with ESRD are evaluated for RRT. kidney transplantation (KTx) is the preferred modality of RRT and dialysis is offered without limitations, if otherwise not contraindicated. Choosing the type of dialysis modality (PD or HD) is based on a shared decision between the patient and the care provider. Age per se is not decisive for providing RRT. The patient's comorbidities, health related problems and personal values are the most important variables in choosing between active RRT and maximal care without RRT. The final decision is made after the patient has received information and education in all aspects of the different modalities in RRT.

This single center study was conducted through retrospective examination of patient charts and data from the local PD complication registry. All patients with ESRD receiving PD-catheters in the county hospital of Vestfold during an 11 year period was included. Standard Tenckhoff catheter was used in all patients. Preoperative antibiotic prophylaxis was not used routinely. The operating surgeon was not a designated PD-surgeon. None of the patients received catheters due to the acute need of PD.

In order to identify risk factors for peritonitis, a multivariate Cox regression was performed and the model was adjusted for clinically relevant factors such as age, gender, occurrence of exit site infection, diabetes mellitus, previous cardiovascular/cerebrovascular disease, body weight, smoking and if the PD was assisted by nurse at home or other institutions.

\section{Results}

101 of the patients with ESRD received PD-catheters during the study period. There was a median delay of 1 month (1-38) before PD was started. Males were predominant $65 \%(n=66)$, with median age of 67 years (18-94). Although fewer, the women tend to be younger, with a median age of 58 years (18-89). ESRD was most commonly caused by hypertension $27 \%$, diabetic nephropathy $16 \%$ : glomerulonephritis $23 \%$.

Few patients had complications associated with PD catheter insertion and only $2.0 \%(\mathrm{n}=2)$ developed postoperative infections. In total, 9 of the patients $(9 \%)$ did not start PD-treatment; 2 (2\%) received kidney trasnplants pre-dialytic, $2 \%(\mathrm{n}=)$ removed the catheter due to infection, $1(1 \%)$ required $\mathrm{HD}$ before $\mathrm{PD}$ could be initiated, 1 (1\%) died and 3(3\%) of the patients were not yet initiated in PD. $89 \%$ $(n=89)$ patients were started on PD and the median time for active PD was 7.0 months (1-30 months).

\section{Exit site infections}

Infections occurred in $43 \%(n=43)$ of the patients. Of these, $23 \%$ $(n=23)$ had one episode, $12 \%(n=12)$ had two episodes and $9 \%(n=9)$ had three or $>3$ episodes. The incidence of exit site infections for the entire cohort is 0.75 episodes per patient year (Figure 1). 
Citation: Bjune T, Kjellevold SA, Abedini S (2020) Infections in Relation to Peritoneal Dialysis: An 11-Year Single Center Experience in Vestfold County, Norway. J Nephrol Renal Ther 6: 029.

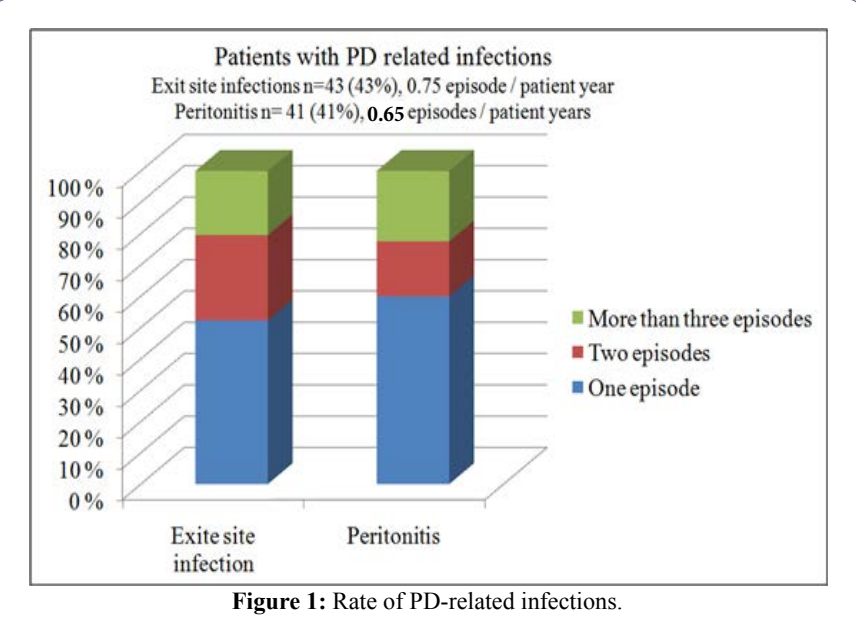

\section{Peritonitis}

41 patients (41\%) developed peritonitis; 24 (24\%) experienced one, 7 (7\%) had two and the rest of the patients $28(28 \%)$ had 3 or $>3$ episodes. The incidence of peritonitis was 0.65 episodes per patient year (Figure 1).

\section{PD discontinuation}

$69 \%(n=69)$ of the patients discontinued PD. $30 \%(n=30)$ received kidney transplants, $14 \%(\mathrm{n}=14)$ due to PD related infections, $8 \%$ $(n=8)$ due to non-infectious complications, 9\% $(n=9)$ patients died during PD and $7 \%(n=7)$ discontinued PD due to terminal disease (Figure 2).

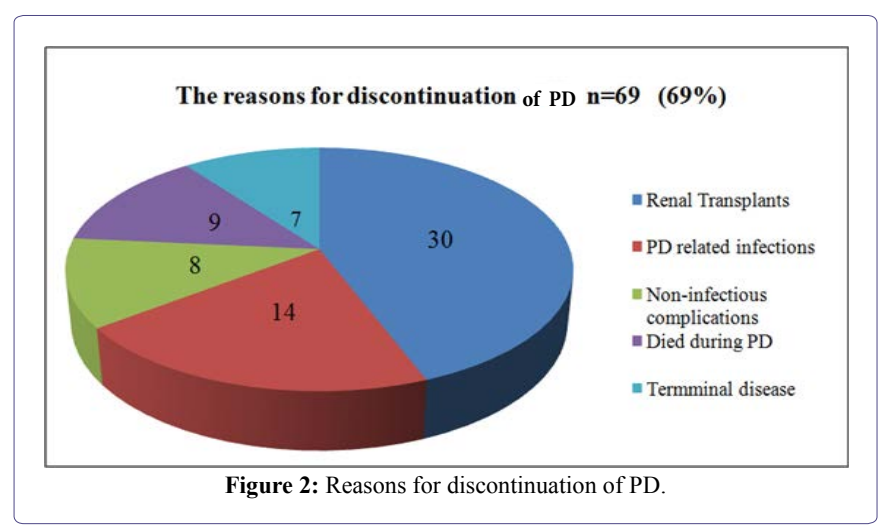

\section{Cause of infections}

Staphylococcus aureus was the cause of both exit site and peritonitis in the majority of the patients.

Patients older than 75 years of age had no significant higher rate of infection compared with younger age groups ( $\log$ rank test $\mathrm{p}=\mathrm{NS})$. Occurrence of both exit site infection and peritonitis was higher in female (Figure 3). Female gender was associated with significantly higher risk of peritonitis in both univariate (Figure 4) and multivariate analysis (HR 0.25, CI: 0.70-0.87) $(\mathrm{p}<0.03)$.

\section{Discussion}

The population of ESRD patients is large and growing [22]. With an increase in metabolic diseases, including DM and HT, an increasing number of patients will converge towards ESRD. Also, a larger part of the population is getting older with increased risk of developing CKD and some may need RRT [23]. In our experience, PD is a good treatment option as RRT and the occurrence of PD-related infections are low and similar to that of HD, even with self-care PD and luckily the general rate is decreasing. This is seen in many recent cohorts despite the fact that medical outcome data would seem to favor more utilization of PD [6,14]. For instance, data from the United States Renal Data Systems suggests that the relative risk of death for patients on PD versus center hemodialysis (CHD).

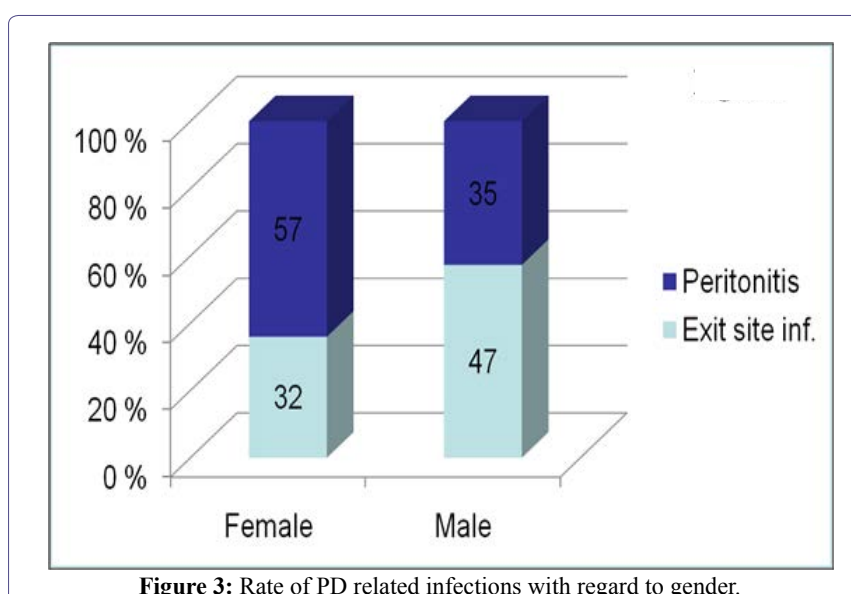

Figure 3: Rate of PD related infections with regard to gender.

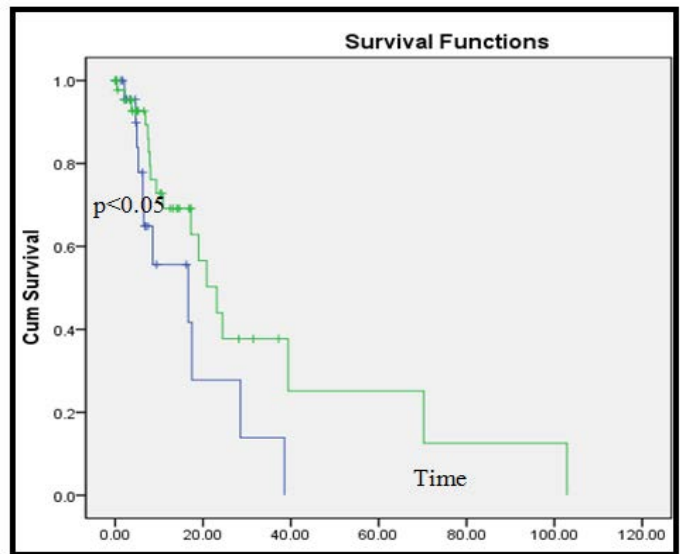

Figure 4: Univariate analysis, Kaplan Mayer curve. Female gender was associated with significantly higher risk of peritonitis in both univariate.

Note: ------- Female; -------- Male

HD carries a higher risk of infections in some studies [6]. However, infections were the reason for conversion to HD in a few patients in this study. In our population, PD is a safe treatment option in both individuals awaiting kidney transplantation and in elderly individuals, with no excess infection rate. The economical aspect that receives great attention in the USA [24], is less important in Norway, where the funding of health care services is covered by the health authorities and all treatments are free of charge for the patient including RRT disregarding the modality [25]. 
Citation: Bjune T, Kjellevold SA, Abedini S (2020) Infections in Relation to Peritoneal Dialysis: An 11-Year Single Center Experience in Vestfold County, Norway. J Nephrol Renal Ther 6: 029.

In this cohort, female gender was associated with higher rate of peritonitis and may need more attention. The results from our study is comparable to the large multicenter study done in Canada in 2009 [21].

\section{Conclusion}

In our experience PD is a safe treatment option regardless of age. Infections related to $\mathrm{PD}$ occurred in acceptable rate in our population. Infections were however the reason for conversion to haemodialysis in few patients. PD is a safe bridge to kidney transplantation and PD is safe treatment option in elderly individuals with no excess infection rate. Female patients might carry a higher risk of infection.

\section{Reference}

1. Hallan SI, Coresh J, Astor BC, Asberg A, Powe NR, et al. (2006) International comparison of the relationship of chronic kidney disease prevalence and ESRD risk. J Am Soc Nephrol 17: 2275-2284.

2. NRR (2018) The Norwegian Renal Registry. Annual report.

3. Machowska A, Rutherford P (2016) Peritoneal dialysis use within the context of the population and healthcare systems of Europe-differences, trends and future challenges. Int J Artif Organs 39: 211-219.

4. Perl J, Davies SJ, Lambie M, Pisoni RL, McCullough K, et al. (2016) The Peritoneal Dialysis Outcomes and Practice Patterns Study (PDOPPS): Unifying efforts to inform practice and improve global outcomes in peritoneal dialysis. Perit Dial Int 36: 297-307.

5. van de Luijtgaarden MW, Jager KJ, Segelmark M, Pascual J, Collart F, et al. (2016) Trends in dialysis modality choice and related patient survival in the ERA-EDTA Registry over a 20-year period. Nephrol Dial Transplant 31: $120-128$.

6. Mehrotra R, Devuyst O, Davies SJ, Johnson DW (2016) The current state of peritoneal dialysis. J Am Soc Nephrol 27: 3238-3252.

7. Tenckhoff H, Schechter H (1968) A bacteriologically safe peritoneal access device. Trans Am Soc Artif Intern Organs 14: 181-187.

8. Oreopoulos DG, Robson M, Izatt S, Clayton S, deVeber GA (1978) A simple and safe technique for Continuous Ambulatory Peritoneal Dialysis (CAPD). Trans Am Soc Artif Intern Organs 24: 484-489.

9. Al-Natour M, Thompson D (2016) Peritoneal Dialysis. Semin Intervent Radiol 33: 3-5.

10. Novak MJ, Sheth H, Bender FH, Fried L, Piraino B (2008) Improvement in Pittsburgh symptom score index after initiation of peritoneal dialysis. Adv Perit Dial 24: 46-50.
11. Chaudhary K, Sangha H, Khanna R (2011) Peritoneal dialysis first: Rationale. Clin J Am Soc Nephrol 6: 447-456.

12. Wolfe RA, Ashby VB, Milford EL, Ojo AO, Ettenger RE, et al. (1999) Comparison of mortality in all patients on dialysis, patients on dialysis awaiting transplantation, and recipients of a first cadaveric transplant. N Engl J Med 341: 1725-1730.

13. Burkart JM (2001) Peritoneal dialysis should be considered as the first line of renal replacement therapy for most ESRD patients. Blood Purif 19: 179-184.

14. Burkart J (2009) The future of peritoneal dialysis in the United States: Optimizing its use. Clin J Am Soc Nephrol 1: 125-131.

15. Klarenbach S, Manns B (2009) Economic evaluation of dialysis therapies. Semin Nephrol 29: 524-532.

16. Davenport A (2009) Peritonitis remains the major clinical complication of peritoneal dialysis: The London, UK, peritonitis audit 2002-2003. Perit Dial Int 29: 297-302.

17. Li PK, Szeto CC, Piraino B, de Arteaga J, Fan S, et al. (2016) ISPD peritonitis recommendations: 2016 update on prevention and treatment. Perit Dial Int 36: 481-508.

18. Szeto CC, Li PK, Johnson DW, Bernardini J, Dong J, et al. (2017) ISPD catheter-related infection recommendations: 2017 update. Perit Dial Int 37: 141-154.

19. Debowski JA, Waerp C, Kjellevold SA, Abedini S (2017) Cuff extrusion in peritoneal dialysis: Single-centre experience with the cuff-shaving procedure in five patients over a 4-year period. Clin Kidney J 10: 131-134.

20. Kawanishi H, Moriishi M (2005) Epidemiology of encapsulating peritoneal sclerosis in Japan. Perit Dial Int 4: 14-18.

21. Nessim SJ, Bargman JM, Austin PC, Nisenbaum R, Jassal SV (2009) Predictors of peritonitis in patients on peritoneal dialysis: Results of a large, prospective Canadian database. Clin J Am Soc Nephrol 4: 1195-1200.

22. Sennfalt K, Magnusson M, Carlsson P (2002) Comparison of hemodialysis and peritoneal dialysis--a cost-utility analysis. Perit Dial Int 22: 39-47.

23. Jha V, Garcia-Garcia G, Iseki K, Li Z, Naicker S, et al. (2013) Chronic kidney disease: global dimension and perspectives. Lancet 382: 260-272.

24. Takemoto Y, Naganuma T (2019) Economic issues of chronic kidney disease and end-stage renal disease. Contrib Nephrol 198: 87-93.

25. The Norwegian Health Care System by Anne Karin Lindahl, Norwegian Knowledge Centre for the Health Services. 


\section{di \\ нвам}

Advances In Industrial Biotechnology | ISSN: 2639-5665

Advances In Microbiology Research | ISSN: 2689-694X

Archives Of Surgery And Surgical Education | ISSN: 2689-3126

Archives Of Urology

Archives Of Zoological Studies | ISSN: 2640-7779

Current Trends Medical And Biological Engineering

International Journal Of Case Reports And Therapeutic Studies | ISSN: 2689-310X

Journal Of Addiction \& Addictive Disorders | ISSN: 2578-7276

Journal Of Agronomy \& Agricultural Science | ISSN: 2689-8292

Journal Of AIDS Clinical Research \& STDs | ISSN: 2572-7370

Journal Of Alcoholism Drug Abuse \& Substance Dependence | ISSN: 2572-9594

Journal Of Allergy Disorders \& Therapy | ISSN: 2470-749X

Journal Of Alternative Complementary \& Integrative Medicine | ISSN: 2470-7562

Journal Of Alzheimers \& Neurodegenerative Diseases | ISSN: 2572-9608

Journal Of Anesthesia \& Clinical Care | ISSN: 2378-8879

Journal Of Angiology \& Vascular Surgery | ISSN: 2572-7397

Journal Of Animal Research \& Veterinary Science | ISSN: 2639-3751

Journal Of Aquaculture \& Fisheries | ISSN: 2576-5523

Journal Of Atmospheric \& Earth Sciences | ISSN: 2689-8780

Journal Of Biotech Research \& Biochemistry

Journal Of Brain \& Neuroscience Research

Journal Of Cancer Biology \& Treatment | ISSN: 2470-7546

Journal Of Cardiology Study \& Research | ISSN: 2640-768X

Journal Of Cell Biology \& Cell Metabolism | ISSN: 2381-1943

Journal Of Clinical Dermatology \& Therapy | ISSN: 2378-8771

Journal Of Clinical Immunology \& Immunotherapy | ISSN: 2378-8844

Journal Of Clinical Studies \& Medical Case Reports | ISSN: 2378-8801

Journal Of Community Medicine \& Public Health Care | ISSN: 2381-1978

Journal Of Cytology \& Tissue Biology | ISSN: 2378-9107

Journal Of Dairy Research \& Technology | ISSN: 2688-9315

Journal Of Dentistry Oral Health \& Cosmesis | ISSN: 2473-6783

Journal Of Diabetes \& Metabolic Disorders | ISSN: 2381-201X

Journal Of Emergency Medicine Trauma \& Surgical Care | ISSN: 2378-8798

Journal Of Environmental Science Current Research | ISSN: 2643-5020

Journal Of Food Science \& Nutrition | ISSN: 2470-1076

Journal Of Forensic Legal \& Investigative Sciences | ISSN: 2473-733X

Journal Of Gastroenterology \& Hepatology Research | ISSN: 2574-2566
Journal Of Genetics \& Genomic Sciences | ISSN: 2574-2485

Journal Of Gerontology \& Geriatric Medicine | ISSN: 2381-8662

Journal Of Hematology Blood Transfusion \& Disorders | ISSN: 2572-2999

Journal Of Hospice \& Palliative Medical Care

Journal Of Human Endocrinology | ISSN: 2572-9640

Journal Of Infectious \& Non Infectious Diseases | ISSN: 2381-8654

Journal Of Internal Medicine \& Primary Healthcare | ISSN: 2574-2493

Journal Of Light \& Laser Current Trends

Journal Of Medicine Study \& Research | ISSN: 2639-5657

Journal Of Modern Chemical Sciences

Journal Of Nanotechnology Nanomedicine \& Nanobiotechnology | ISSN: 2381-2044 Journal Of Neonatology \& Clinical Pediatrics | ISSN: 2378-878X

Journal Of Nephrology \& Renal Therapy | ISSN: 2473-7313

Journal Of Non Invasive Vascular Investigation | ISSN: 2572-7400

Journal Of Nuclear Medicine Radiology \& Radiation Therapy | ISSN: 2572-7419

Journal Of Obesity \& Weight Loss | ISSN: 2473-7372

Journal Of Ophthalmology \& Clinical Research | ISSN: 2378-8887

Journal Of Orthopedic Research \& Physiotherapy | ISSN: 2381-2052

Journal Of Otolaryngology Head \& Neck Surgery | ISSN: 2573-010X

Journal Of Pathology Clinical \& Medical Research

Journal Of Pharmacology Pharmaceutics \& Pharmacovigilance | ISSN: 2639-5649

Journal Of Physical Medicine Rehabilitation \& Disabilities | ISSN: 2381-8670

Journal Of Plant Science Current Research | ISSN: 2639-3743

Journal Of Practical \& Professional Nursing | ISSN: 2639-5681

Journal Of Protein Research \& Bioinformatics

Journal Of Psychiatry Depression \& Anxiety | ISSN: 2573-0150

Journal Of Pulmonary Medicine \& Respiratory Research | ISSN: 2573-0177

Journal Of Reproductive Medicine Gynaecology \& Obstetrics | ISSN: 2574-2574

Journal Of Stem Cells Research Development \& Therapy | ISSN: 2381-2060

Journal Of Surgery Current Trends \& Innovations | ISSN: 2578-7284

Journal Of Toxicology Current Research | ISSN: 2639-3735

Journal Of Translational Science And Research

Journal Of Vaccines Research \& Vaccination | ISSN: 2573-0193

Journal Of Virology \& Antivirals

Sports Medicine And Injury Care Journal | ISSN: 2689-8829

Trends In Anatomy \& Physiology | ISSN: 2640-7752

Submit Your Manuscript: https://www.heraldopenaccess.us/submit-manuscript 